\title{
Acquired resistance to miriplatin in rat hepatoma AH109A/MP10 is associated with increased Bcl-2 expression, leading to defects in inducing apoptosis
}

\author{
MITSUHARU HANADA $^{1}$, HIDEO TAKASU ${ }^{1}$ and MAKOTO KITAURA ${ }^{2}$ \\ ${ }^{1}$ Pharmacology Research Laboratories, Dainippon Sumitomo Pharma Co., Ltd., 3-1-98 Kasugadenaka, \\ Konohana-ku, Osaka 554-0022; ${ }^{2}$ Research Planning and Management, Dainippon Sumitomo Pharma Co., Ltd., \\ 2-6-8 Doshomachi, Chuo-ku, Osaka 541-0045, Japan
}

Received March 30, 2010; Accepted May 7, 2010

DOI: $10.3892 /$ or_00000949

\begin{abstract}
Miriplatin, a novel lipophilic platinum complex approved to treat hepatocellular carcinoma, is administered into the hepatic artery after suspension in an oily contrast medium. Little is known concerning the mechanism of acquired resistance to miriplatin. In this study, we established and characterized a rat hepatoma cell subline, AH109A/ MP10, which was about 10-fold more resistant to miriplatin than the parental cell line, AH109A. The established miriplatin-resistant cells showed clear cross-resistance to platinum complexes containing diaminocyclohexane as a carrier ligand, such as oxaliplatin and dichloro[ $[(R, 2 R)-1,2$-cyclohexanediamine- $N, N^{\prime}$ ]platinum (DPC), while three human cancer cell lines selected for resistance to cisplatin (A2780cis, NCI-H69/CPR, MOR/CPR) did not show cross-resistance to miriplatin. There was no apparent difference in either intracellular platinum accumulation or platinum-DNA adducts in formation between resistant and parental cells after treatment with miriplatin or cisplatin, consisted with the unchanged expression of proteins involved in DNA repair, such as excision repair cross-complementing 1 (ERCC1) and mutL homolog 1 (MLH1). The increased expression of $\mathrm{Bcl}-2$ was observed in AH109A/MP10 cells, in which apoptosis induced by miriplatin, but not cisplatin, was reduced. In addition, Bcl-2 inhibitor YC137 partially reversed the resistance of AH109A/MP10 cells to miriplatin. These findings suggested that the acquired resistance to miriplatin in AH109A/MP10 cells was associated in part with increased Bcl-2 expression, leading to defects in inducing apoptosis.
\end{abstract}

Correspondence to: Dr Mitsuharu Hanada, Pharmacology Research Laboratories, Dainippon Sumitomo Pharma Co., Ltd., 3-1-98 Kasugadenaka, Konohana-ku, Osaka 554-0022, Japan E-mail: mitsuharu-hanada@ds-pharma.co.jp

Key words: miriplatin, cisplatin, acquired resistance, Bcl-2, hepatocellular carcinoma

\section{Introduction}

Most patients with hepatocellular carcinoma (HCC) are diagnosed at the intermediate to advanced stage with hepatic impairment caused by virus-associated cirrhosis or chronic hepatitis. For these patients, transarterial chemoembolization (TACE) is a treatment option with a survival benefit. Actually, recent randomized controlled trials indicated that TACE induced marked objective responses and improved the survival of selected patients with HCC $(1,2)$. TACE is based on the fact that HCC is fed exclusively by the hepatic artery, while the normal liver has a dual blood supply from the hepatic artery and the portal vein (3). Ethyl ester of iodized fatty acids obtained from poppy seed oil (iodinated poppy seed oil), an oily contrast medium for diagnosis, is selectively retained in tumors when injected into the hepatic artery, and is used as a vehicle to carry and localize antitumor agents, such as cisplatin, doxorubicin, and mitomycin $\mathrm{C}$ in hepatic tumors (3); however, there is no good evidence for the best antitumor agent, probably because most of those currently used for TACE are not able to utilize iodinated poppy seed oil as the carrier solvent due to their water solubility.

Miriplatin (formerly SM-11355) containing myristates as leaving groups and diaminocyclohexane (DACH) as a carrier ligand has been chemically designed to be a lipophilic platinum complex which can be easily suspended in iodinated poppy seed oil (4). In several animal models where tumors were implanted in the liver, miriplatin suspended in iodinated poppy seed oil (miriplatin suspension) showed favorable antitumor activities after intra-hepatic arterial administration, suggesting that miriplatin is a suitable candidate for use in TACE (5-8). In an early phase II study of chemotherapy-naïve patients with $\mathrm{HCC}, 9$ of 16 patients who were treated with miriplatin suspension achieved a complete response, defined as the disappearance or $100 \%$ necrosis of all tumors (9). Miriplatin suspension showed similar efficacy to that of zinostatin stimalamer suspended in iodinated poppy seed oil, and repeated dosing was possible without hepatic vascular injury in a randomized late phase II study in patients with unresectable HCC (10). Based on these clinical studies, miriplatin has been approved for lipiodolization for the treatment of HCC in Japan. Recently, a randomized phase III 
study started with miriplatin in the TACE setting for HCC using epirubicin as a control.

HCC is characterized by the multicentric development of de novo tumors and the high incidence of intra-hepatic metastasis because the underlying cirrhosis constitutes a preneoplastic state (11). Frequent follow-up post-treatment and early detection of recurrence as well as complete control of primary $\mathrm{HCC}$ are necessary to achieve a better outcome. In order to control local tumors, prevent tumor progression, and prolong survival, TACE is performed repeatedly, changing the antitumor agents or the tumor vessels to be administered while objective responses are obtained. Therefore, intrinsic or acquired resistance to antitumor agents is considered to be one of the limitations for successful TACE. To date, little is known about the mechanism of acquired resistance to miriplatin. In this study, we described the development and characterization of a rat hepatoma cell line AH109A/MP10, selected for its resistance to miriplatin.

\section{Materials and methods}

Chemicals. Miriplatin ((SP-4-2)-[(1R,2R)-cyclohexane1,2 -diamine- $\left.N, N^{\prime}\right]$ bis (tetradecanoato- $O$ ) platinum) and dichloro[(1R,2R)-1,2-cyclohexanediamine- $\left.N, N^{\prime}\right]$ platinum (DPC) were prepared by Dainippon Sumitomo Pharma Co., Ltd. (Osaka, Japan). Cisplatin, oxaliplatin, carboplatin, and nedaplatin were obtained from Nihon Kayaku Co., Ltd. (Tokyo, Japan), LKT Laboratories, Inc. (St. Paul, MN), Bristol-Myers Squibb Company (New York, NY), and Shionogi Co., Ltd. (Osaka, Japan), respectively. Mitomycin C, 5-fluorouracil, doxorubicin, and epirubicin were from Kyowa Hakko (Tokyo, Japan). Zinostatin stimalamer and ethyl esters of iodized fatty acids of poppy seed oil were from Astellas Pharma Inc. (Tokyo, Japan) and TERUMO Corp. (Tokyo, Japan), respectively.

Cell lines and the establishment of AH109A/MP10 subline. The rat ascite hepatoma cell line AH109A was provided by Kumamoto University (Kumamoto, Japan). The cells were maintained in RPMI-1640 medium supplemented with antibiotics (penicillin and streptomycin) and 10\% heat-inactivated fetal bovine serum (FBS). The resistant subline, AH109A/ MP10, was established by stepwise exposure of AH109A to increasing concentration of miriplatin suspension $(3,10,30$ and $100 \mu \mathrm{g} / \mathrm{ml}$ in iodinated poppy seed oil) over a period of twelve months. The human ovarian cancer cell line A2780, its cisplatin-resistant subline A2780cis, human small-cell lung carcinoma cell line H69, its cisplatin-resistant subline NCI-H69/CPR, human lung adenocarcinoma cell line MOR, and its cisplatin-resistant subline MOR/CPR were obtained from the European Collection of Cell Cultures (Salisbury, UK) and maintained in RPMI-1640 medium supplemented with antibiotics and $10 \%$ heat-inactivated FBS. All cell lines were cultured at $37^{\circ} \mathrm{C}$ in $5 \% \mathrm{CO}_{2} / 95 \%$ air.

In vitro cell proliferation assay. Aliquots of cells were plated into 24-well microplates. Following cell adherence (one day), iodinated poppy seed oil alone or agents suspended in iodinated poppy seed oil were added to Falcon cell culture inserts (Becton-Dickinson and Company, Franklin Lakes,

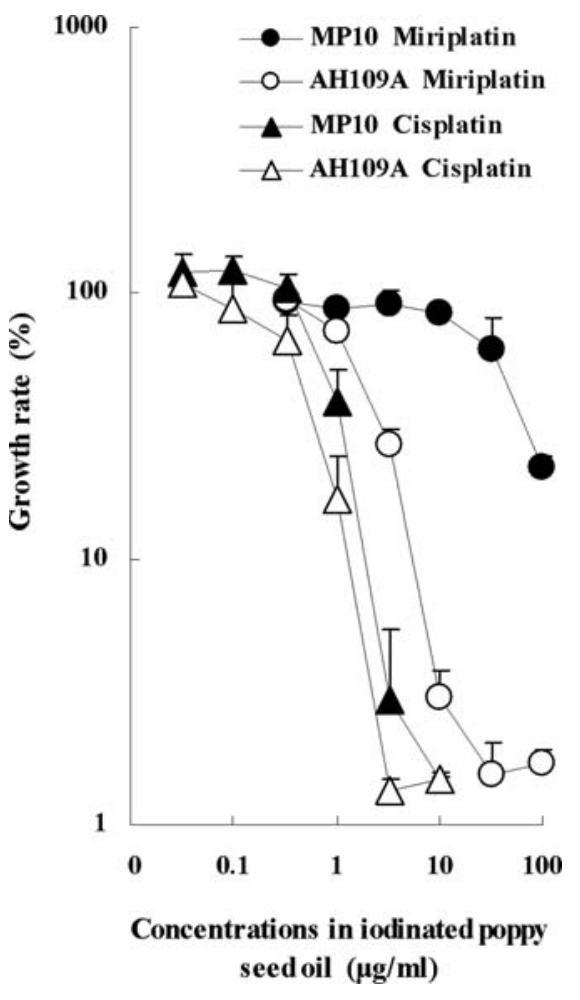

Figure 1. Effects of miriplatin suspension or cisplatin suspension on the cell growth of AH109A and AH109A/MP10. One day after plating AH109A cells and AH109A/MP10 cells in microplates, miriplatin suspension or cisplatin suspension was added to Falcon cell culture inserts. Cells were exposed to agents at the indicated concentrations in iodinated poppy seed oil for seven days at $37^{\circ} \mathrm{C}$ in $5 \% \mathrm{CO}_{2}$. Growth rate was calculated as the ratio of the number of cells treated by agents to that by iodinated poppy seed oil alone. All results are given as the mean \pm SD of triplicates.

$\mathrm{NJ}$ ), equipped with a $0.4-\mu \mathrm{m}$ pore membrane on their bottom. After seven days of incubation at $37^{\circ} \mathrm{C}$ in $5 \% \mathrm{CO}_{2}$, the numbers of viable cells were examined using AlamarBlue (Trek Diagnostic Systems, Westlake, OH). In experiments to test the effect of Bcl-2 inhibitor on cell growth, cells were pretreated with increasing concentrations of YC137 (EMD Chemicals Inc., Darmstadt, Germany) or $0.2 \%$ (v/v) DMSO, and treated with iodinated poppy seed oil alone or agents suspended in iodinated poppy seed oil. The $\mathrm{IC}_{50}$ value was defined as the concentration of agents inhibiting cell growth by $50 \%$ compared with treatment by iodinated poppy seed oil alone. Alternatively, aliquots of cells were plated into 96-well microplates. Following cell adherence (one day), agents in aqueous solution were added. After seven days of incubation at $37^{\circ} \mathrm{C}$ in $5 \% \mathrm{CO}_{2}$, the numbers of viable cells were examined using AlamarBlue.

Assessment of cellular platinum accumulation and platinumDNA adducts. After three days of treatment with agents, cells were lysed in $50 \mathrm{mM}$ Tris- $\mathrm{HCl}, 150 \mathrm{mM} \mathrm{NaCl}, 10 \mathrm{mM}$ EDTA (pH 8.0), and 0.5\% SDS. DNA was isolated from cells using DNAzol reagent (Invitrogen Corp., Carlsbad, CA) in accordance with the manufacturer's protocol, and was solubilized in Tris-buffered EDTA. Platinum concentrations in lysates or DNA were quantitatively analyzed at $265.9 \mathrm{~nm}$ by flameless atomic absorption spectrometry (FAAS) Z-9000 
Table I. Sensitivities to antitumor agents of AH109A cells and AH109A/MP10 cells.

\begin{tabular}{|c|c|c|c|c|}
\hline & \multicolumn{3}{|c|}{$\mathrm{IC}_{50}(\mu \mathrm{g} / \mathrm{ml})$} & \multirow[b]{2}{*}{ Resistance factor } \\
\hline & Agents & AH109A & AH109A/MP10 & \\
\hline \multirow[t]{2}{*}{ Suspension } & Miriplatin & $2.3 \pm 2.8$ & $22 \pm 16$ & 9.6 \\
\hline & Cisplatin & $0.41 \pm 0.20$ & $0.53 \pm 0.42$ & 1.3 \\
\hline \multirow[t]{10}{*}{ Aqueous solution } & $\mathrm{DPC}$ & $0.059 \pm 0.036$ & $0.43 \pm 0.13$ & 7.3 \\
\hline & Oxaliplatin & $0.27 \pm 0.10$ & $1.4 \pm 0.8$ & 5.3 \\
\hline & Cisplatin & $0.090 \pm 0.056$ & $0.077 \pm 0.017$ & 0.86 \\
\hline & Nedaplatin & $0.14 \pm 0.11$ & $0.16 \pm 0.03$ & 1.1 \\
\hline & Carboplatin & $1.1 \pm 1.0$ & $0.71 \pm 0.20$ & 0.66 \\
\hline & Mitomycin C & $0.0076 \pm 0.0048$ & $0.0078 \pm 0.0045$ & 1.0 \\
\hline & Doxorubicin & $0.025 \pm 0.009$ & $0.0058 \pm 0.0010$ & 0.23 \\
\hline & Epirubicin & $0.019 \pm 0.008$ & $0.0055 \pm 0.0028$ & 0.29 \\
\hline & Zinostatin stimalamer & $0.020 \pm 0.007$ & $0.0089 \pm 0.0038$ & 0.45 \\
\hline & 5-fluorouracil & $0.14 \pm 0.06$ & $0.054 \pm 0.021$ & 0.38 \\
\hline
\end{tabular}

One day after plating cells in microplates, cells were exposed to agents for seven days at $37^{\circ} \mathrm{C}$ in $5 \% \mathrm{CO}_{2}$. All $\mathrm{IC}_{50}$ values are given as the mean $\pm \mathrm{SD}$ of four or five independent experiments. The resistance factor was calculated as the ratio of the mean $\mathrm{IC}_{50}$ in $\mathrm{AH} 109 \mathrm{~A} / \mathrm{MP} 10$ cells to the mean $\mathrm{IC}_{50}$ in $\mathrm{AH} 109 \mathrm{~A}$ cells.

(Hitachi, Tokyo, Japan). The DNA content was assessed fluorometrically using Hoechst 33258.

Western blot analysis. Cells were lysed in the buffer containing $100 \mathrm{mM}$ Tris- $\mathrm{HCl}$ (pH 8.0), $300 \mathrm{mM} \mathrm{NaCl}, 5 \mathrm{mM}$ EDTA, $1 \%$ Nonidet P-40, and 1\% protease inhibitor cocktail (Sigma-Aldrich, St. Louis, MO). Extracts (30-40 $\mu \mathrm{g}$ protein) were separated by $12.5 \%$ SDS-PAGE and transferred to a PVDF membrane by electroblotting. Blots were blocked over $3 \mathrm{~h}$ in Block Ace (DS Pharma Biomedical, Osaka, Japan), incubated overnight with primary antibodies, and then washed three times with $0.1 \mathrm{X}$ Block Ace containing $0.1 \%$ Tween-20 at room temperature. Primary antibodies were anti-excision repair cross-complementing 1 (ERCC1) mouse monoclonal antibody, anti-xeroderma pigmentosum group F (XPF) rabbit polyclonal antibody, anti-DNA polymerase $\beta$ goat polyclonal antibody, anti-DNA polymerase $\eta$ goat polyclonal antibody, anti-mutS homolog 6 (MSH6) rabbit polyclonal antibody, anti-mutS homolog 2 (MSH2) rabbit polyclonal antibody, anti-postmeiotic segregation increased 2 (PMS2) rabbit polyclonal antibody, anti-mutL homolog 1 (MLH1) rabbit polyclonal antibody, anti-Bcl-2associated $\mathrm{X}$ protein (Bax) rabbit polyclonal antibody, antiBH3 interacting domain death agonist (Bid) rabbit polyclonal antibody, anti-p53 up-regulate modulator of apoptosis (PUMA) $\alpha / \beta$ rabbit polyclonal antibody anti-Bcl- $\mathrm{X}_{\mathrm{L}}$ rabbit polyclonal antibody, and anti-Bcl-2 rabbit polyclonal antibody (Santa Cruz Biotechnology, Santa Cruz, CA). Blots were then incubated over $3 \mathrm{~h}$ at room temperature in $0.1 \mathrm{X}$ Block Ace containing alkaline phosphatase-conjugated secondary antibodies (Zymed Laboratories, South San Francisco, CA), followed by detection with alkaline phosphatase conjugate substrate kit (Bio-Rad Laboratories, Hercules, CA). To confirm equivalent loading and transfer of proteins, anti- $\beta$ actin rabbit monoclonal antibody (Epitomics, Burlingame, CA) was used.

Induction of apoptosis within cultured cells. The apoptosis of cells was assessed as the fraction with sub- $\mathrm{G}_{1}$ DNA content. Cells were fixed in $80 \%$ ethanol for $20 \mathrm{~min}$ at room temperature. Following treatment with $1 \mathrm{mg} / \mathrm{ml}$ RNase A for $20 \mathrm{~min}$ at $37^{\circ} \mathrm{C}$, cells were stained in a propidium iodide solution $(50 \mu \mathrm{g} / \mathrm{ml}$ propidium iodide in $0.1 \%$ sodium citrate and $0.1 \%$ Triton $\mathrm{X}-100)$ and then analyzed using a FACScan flow cytometer (Becton-Dickinson and Company).

\section{Results}

Acquired resistance to miriplatin and cross-resistance to other antitumor agents. Representative in vitro antitumor activities of miriplatin suspension in AH109A cells and AH109A/MP10 cells are shown in Fig. 1. Approximately 10 -fold higher concentration of miriplatin suspension was required to inhibit the growth of AH109A/MP10 cells compared to parental cells (Table I). In contrast, there was no apparent difference in their sensitivities to cisplatin suspended in iodinated poppy seed oil (cisplatin suspension). Table I also shows the sensitivity profiles of AH109A cells and AH109A/MP10 cells to other platinum complexes (DPC, oxaliplatin, nedaplatin, and carboplatin) and antitumor agents used for TACE (mitomycin C, doxorubicin, epirubicin, zinostatin stimalamer, and 5-fluorouracil). AH109A/MP10 cells showed clear cross-resistance to DPC and oxaliplatin with $>5$-fold higher $\mathrm{IC}_{50}$ values, but not to the other agents tested. 
Table II. Sensitivities to miriplatin of cisplatin-resistant human cancer cell lines.

\begin{tabular}{lcccc}
\hline & \multicolumn{2}{c}{ Miriplatin suspension } & \multicolumn{2}{c}{ Cisplatin suspension } \\
\cline { 2 - 4 } Cell lines & $\mathrm{IC}_{50}(\mu \mathrm{g} / \mathrm{ml})$ & Resistance factor & & Resistance factor \\
\hline A2780 & $1.9 \pm 0.6$ & & $2.7 \pm 2.2$ & \\
A2780cis & $3.1 \pm 0.8$ & 1.6 & $7.4 \pm 5.0$ & 2.7 \\
NCI-H69 & $1.5 \pm 1.2$ & & $0.44 \pm 0.15$ & 10 \\
NCI-H69/CPR & $3.8 \pm 2.9$ & 2.5 & $4.5 \pm 3.9$ & \\
MOR & $3.2 \pm 1.5$ & & $0.65 \pm 0.33$ & 9.5 \\
MOR/CPR & $5.7 \pm 2.3$ & 1.8 & $6.2 \pm 3.6$ & \\
\hline
\end{tabular}

One day after plating cells in microplates, miriplatin or cisplatin suspension was added to Falcon cell culture inserts. Cells were exposed to agents for seven days at $37^{\circ} \mathrm{C}$ in $5 \% \mathrm{CO}_{2}$. All $\mathrm{IC}_{50}$ values are given as the mean $\pm \mathrm{SD}$ of five independent experiments. The resistance factor was calculated as the ratio of the mean $\mathrm{IC}_{50}$ in cisplatin-resistant cells to the mean $\mathrm{IC}_{50}$ in parental cells.
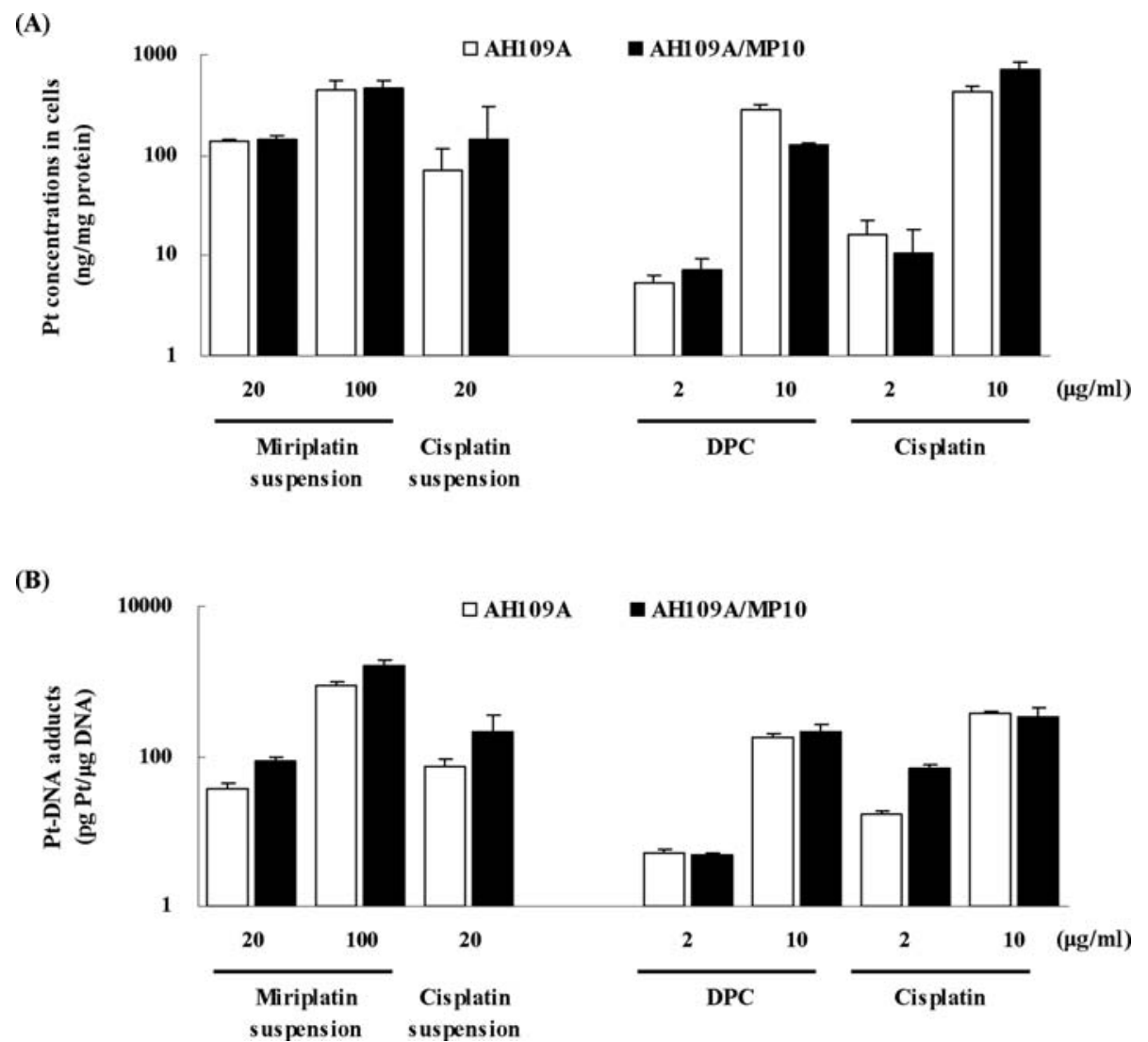

Figure 2. Cellular platinum accumulation and platinum-DNA adduct formation in AH109A cells and AH109A/MP10 cells. (A) One day after plating AH109A and AH109A/MP10 in microplates, miriplatin or cisplatin suspension was added to Falcon cell culture inserts. Alternatively, DPC or cisplatin (without iodinated poppy seed oil) was added to medium. Cells were exposed to agents at the indicated concentrations for three days at $37^{\circ} \mathrm{C}$ in $5 \% \mathrm{CO}_{2}$. Platinum concentrations in cell lysates were quantitatively analyzed by FASS. All results are given as the mean \pm SD ( $n=3$ to 9 ). (B) Cells were exposed to agents as described above. After DNA was isolated from cells, platinum concentrations in DNA were quantitatively analyzed by FASS. All results are given as the mean $\pm \mathrm{SD}(\mathrm{n}=3$ or 6$)$.

These results indicated that AH109A/MP10 cells were selectively resistant to platinum complexes containing DACH as a carrier ligand.

Oxaliplatin, a platinum complex with the DACH carrier ligand, has been widely regarded as potentially useful for the treatment of cisplatin-resistant cancer, based on preclinical evidence indicating that oxaliplatin has some activity in highly cisplatin-resistant cell lines (12). To evaluate crossresistance, we examined the sensitivities of miriplatin suspension to three established cisplatin-resistant human cancer cell lines (Table II). A2780cis cells, NCI-H69/CPR cells and MOR/CPR cells were 2.7-, 10- and 9.5-fold 


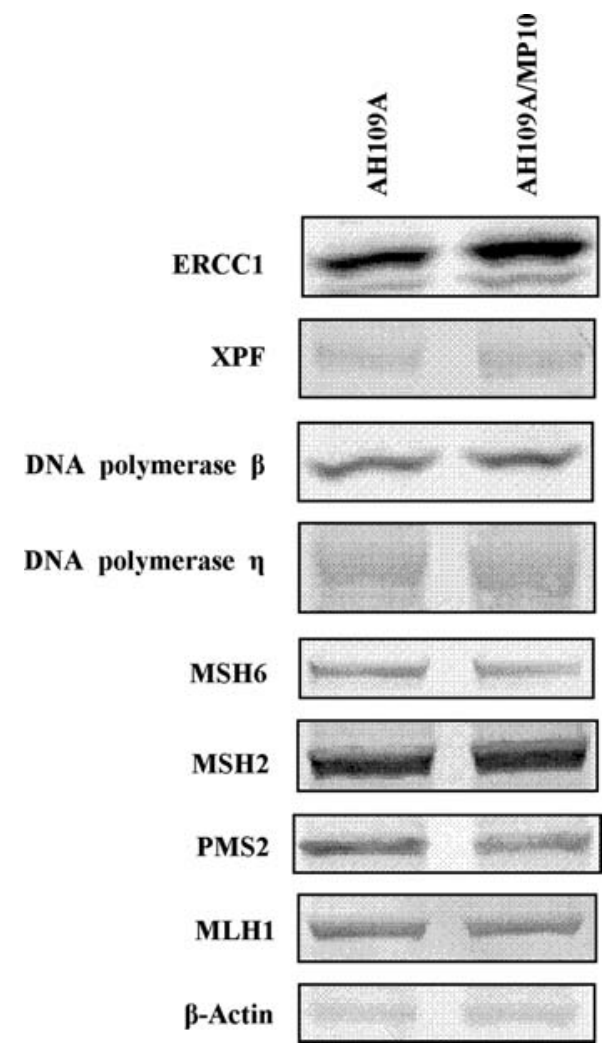

Figure 3. Expression of DNA repair enzymes in AH109A cells and AH109A/ MP10 cells. The same amount (30-40 $\mu \mathrm{g}$ of proteins) of lysate prepared from untreated cells were separated by SDS-PAGE and transferred to PVDF membranes. The expression of eight proteins involved in DNA repair was analyzed by Western blot analysis. B-actin is shown as a loading and transferring control.

resistant to cisplatin suspension, while they were 1.6-, 2.5and 1.8 -fold resistant to miriplatin suspension, respectively, indicating no cross-resistance to miriplatin.

Cellular platinum accumulation and the formation of platinum-DNA adducts. Multidrug resistance is seen most frequently in cells resistant to various antitumor agents, and is caused by membrane transporters which reduce intracellular drug concentrations (13). To assess the mechanism of acquired resistance to miriplatin in AH109A/MP10 cells, intracellular platinum concentrations were measured three days after treatment with miriplatin suspension or DPC, one of reactive species of miriplatin (Fig. 2A). Platinum accumulation following treatment with two concentrations was compatible in both cells. We also could not observe reduced cellular platinum accumulation after treatment with cisplatin as a suspension or aqueous solution. These results suggested that miriplatin resistance in AH109A/MP10 cells was independent of reduced drug accumulation.

Increased detoxification by glutathione or metallothionein is also known to be one of factors contributing to the resistance to several antitumor platinum complexes due to the decrease in platinum-DNA adduct formation (13). Thus, we determined whether reduced platinum-DNA adduct formation contributes to the acquired miriplatin resistance. Levels of platinum-DNA adducts formed in AH109A/MP10 cells were not lower than those in parental cells after 3-day treatment with miriplatin suspension, DPC or cisplatin (Fig. 2B). These results suggested that there was no apparent difference in platinum-DNA adduct formation between AH109A/MP10 cells and parental cells.

Expression of proteins involved in DNA repair. To confirm that AH109A/MP10 cells retain the ability to repair platinumDNA adducts, similar to parental cells, we performed Western blots of eight proteins involved in DNA repair (Fig. 3). Nucleotide excision repair proteins have been shown to contribute to platinum resistance. Both ERCC1 and XPF, which accelerated the removal of platinum-DNA adducts (14), were not reduced in AH109A/MP10 cells compared to parental cells. Loss of mismatch repair proteins is also associated with cisplatin resistance, and DNA polymerases involved in translesion synthesis (or replicative bypass) may contribute to the tolerance to antitumor platinum complex (14). There was no apparent change in the expression level of $\mathrm{MSH} 2$, MSH6, PMS2, MLH1, DNA polymerase $B$, or DNA polymerase $\eta$ between the two cells. From these results, AH109A/ MP10 cells appeared to retain the ability to recognize and repair platinum-DNA adducts, similar to parental cells.

Defects in apoptotic response caused by increased Bcl-2. To compare the ability of miriplatin suspension and cisplatin suspension to induce apoptosis, we measured the populations of sub- $\mathrm{G}_{1}$ apoptotic cells treated with them for three days by flow cytometric analysis. As shown in Fig. 4A, cisplatin suspension induced apoptosis in both cells with similar efficacy, while both miriplatin suspension and DPC failed to induce apoptosis efficiently in AH109A/MP10 cells compared to AH109A cells. Approximately 10-fold higher concentrations of miriplatin suspension or DPC were required to increase in sub- $\mathrm{G}_{1}$ cells of AH109A/MP10 cells compared to those of parental cells, reflecting the difference in $\mathrm{IC}_{50}$ values between them. Accordingly, the resistance phenotype could be associated with defects in triggering apoptosis after platinum-DNA adduct formation.

Defects in the apoptotic response in cancer cells are associated with resistance to various chemotherapeutic agents. Bcl-2 family proteins constitute a critical control point in apoptosis regulating mitochondrial permeability transition, which leads to the release of apoptotic factors (15). To assess the contribution of $\mathrm{Bcl}-2$ family proteins to the resistance to miriplatin, we compared the expressions of three proapoptotic proteins and two anti-apoptotic proteins between the two cell types (Fig. 4B). Although there was no apparent change in the expression levels of Bax, Bid, PUMA, and Bcl- $\mathrm{x}_{\mathrm{L}}$, the anti-apoptotic Bcl-2 protein level in AH109A/ MP10 cells was 3 to 4 times higher than in parental cells.

Partial reversal of resistance to miriplatin in AH109A/MP10 in the presence of $\mathrm{Bcl}-2$ inhibitor. YC137 inhibits the binding of Bcl-2 homology 3 peptide derived from Bid to $\mathrm{Bcl}-2$ thereby blocking the anti-apoptotic activity of Bcl-2 (16). To further evaluate whether the increased expression of Bcl-2 could contribute to the acquired resistance to miriplatin in AH109A/MP10 cells, in vitro antitumor activities of miriplatin suspension were compared between resistant and parental cells in the presence of YC137. Partial reversal of the resis- 
(A)
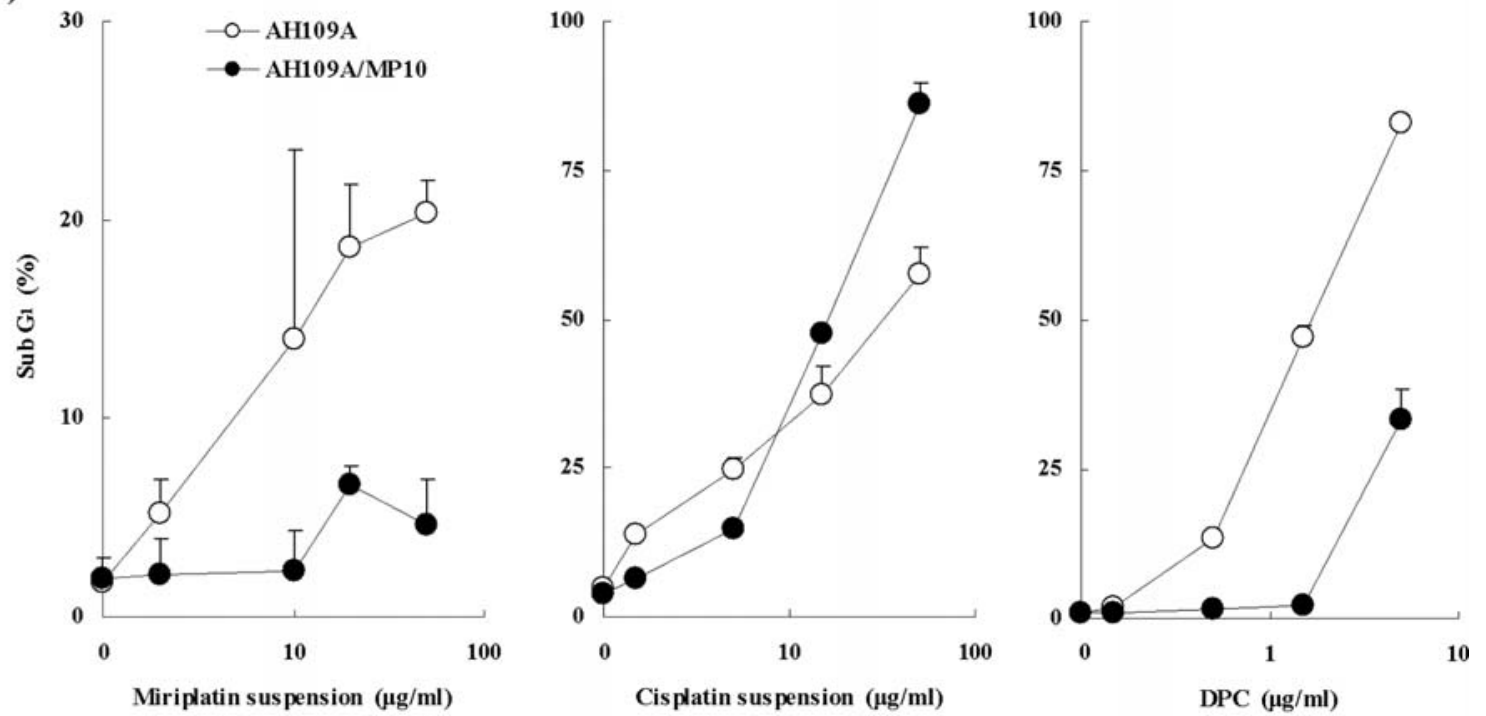

(B)

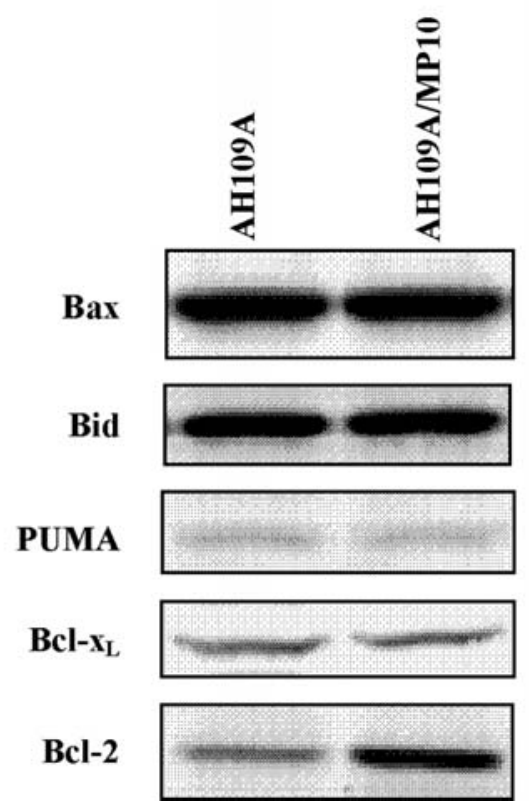

tance of AH109A/MP10 cells to miriplatin was observed by treating cells with YC137 (Fig. 5). YC137 did not influence cisplatin suspension sensitivity in AH109A/MP10 cells or miriplatin suspension sensitivity in parental cells under the condition used. YC137 alone at higher concentrations inhibited the growth of the two cells (data not shown), because they expressed Bcl-2. These results suggested that pharmacological inhibition of Bcl-2 in AH109A/MP10 cells rendered them more sensitive to miriplatin, but not to cisplatin.

\section{Discussion}

TACE is a treatment option with a survival benefit for patients with $\mathrm{HCC}$ who are diagnosed at the intermediate to advanced stage with hepatic impairment caused by virusassociated cirrhosis or chronic hepatitis. In order to control

Figure 4. Induction of apoptosis and expression of Bcl-2 family proteins in AH109A cells and AH109A/MP10 cells. (A) AH109A cells and AH109A/ MP10 cells were exposed to agents at the indicated concentrations for three days at $37^{\circ} \mathrm{C}$ in $5 \% \mathrm{CO}_{2}$. The population of sub- $\mathrm{G}_{1}$ cells was determined by flow cytometry after propidium iodide staining. All data are shown as the mean $\pm \mathrm{SD}$ ( $\mathrm{n}=3$ or 6 ). (B) Same amounts (30-40 $\mu \mathrm{g}$ of proteins) of lysates prepared from untreated cells were separated by SDS-PAGE and transferred to PVDF membranes. The expression of $\mathrm{Bcl}-2$ family proteins was analyzed by Western blot analysis.

local tumors, prevent tumor progression, and prolong survival, TACE is performed repeatedly, changing the antitumor agents or tumor vessels to be administered during the time objective responses are obtained. Therefore, intrinsic or acquired resistance to antitumor agents is considered to be one of the limitations for successful TACE. Acquired resistance to antitumor platinum complexes has been extensively studied and found to be multifactorial, consisting of decreased drug accumulation mediated by overexpression of transporters, increased detoxification by glutathione or metallothionein, and increased tolerance/repair of DNA damage $(13,14,17)$. The miriplatin-resistant rat hepatoma subline AH109A/MP10 established in this study was selectively resistant to DPC and oxaliplatin, which contained DACH as a carrier ligand, but not to other antitumor platinum complexes, such as cisplatin, carboplatin, and nedaplatin, which shared cis-diammine carrier ligands. Although DPC has been shown to be the most abundant platinum compound released from miriplatin suspension, and to be as effective as 

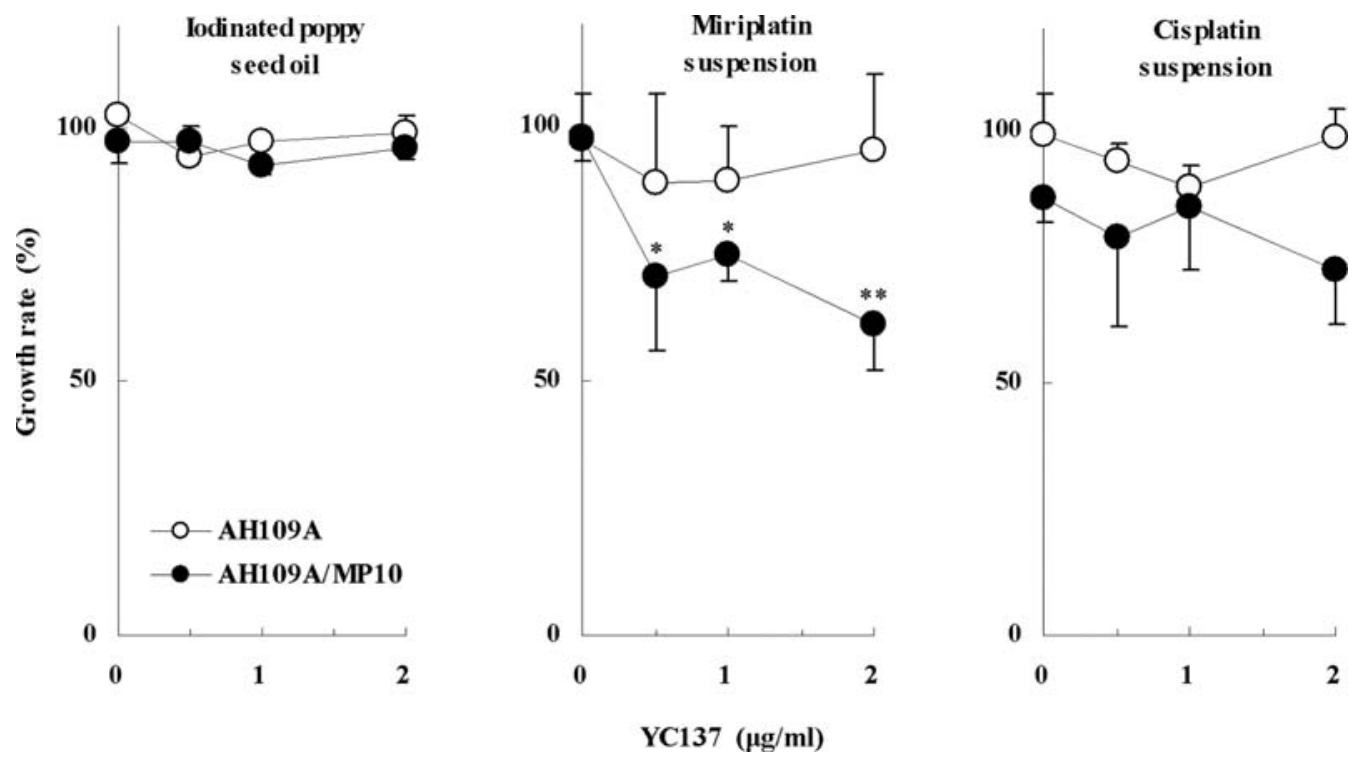

Figure 5. Effect of Bcl-2 inhibitor on the growth inhibition by miriplatin suspension or cisplatin suspension in AH109A cells and AH109A/MP10 cells. One day after plating AH109A cells and AH109A/MP10 cells in microplates, cells were pre-treated with the indicated concentrations of YC137. Then, iodinated poppy seed oil alone (left), miriplatin suspension (middle), or cisplatin suspension (right) was added to Falcon cell culture inserts. AH109A cells and AH109A/MP10 cells were exposed to 4 and $40 \mu \mathrm{g} / \mathrm{ml}$ miriplatin suspension, respectively, and both were exposed to $1 \mu \mathrm{g} / \mathrm{ml}$ cisplatin suspension for seven days at $37^{\circ} \mathrm{C}$ in $5 \% \mathrm{CO}_{2}$. All results are given as the mean $\pm \mathrm{SD}$ of three independent experiments. A Dunnett test of the growth rate demonstrated a significant difference, ${ }^{*} \mathrm{p}<0.05,{ }^{* *} \mathrm{p}<0.01$, comparing the group treated without $\mathrm{YC} 137$ to those treated with the increasing concentrations of $\mathrm{YC} 137$.

cisplatin in inhibiting the growth of hepatic cancer cell lines $(6,7)$, it has not been fully confirmed which role DPC played in the antitumor activities of miriplatin. The clear crossresistance between miriplatin and DPC supports that DPC could be one of active species of miriplatin. Miriplatinresistant AH109A/MP10 cells retained their sensitivity to cisplatin, while three cisplatin-resistant human cancer cell lines tested in this study and cisplatin-resistant rat hepatoma cell line H4-II-E/CDDP showed no cross-resistance to miriplatin (18). These results suggested that miriplatin might have some activity in cisplatin-resistant HCC. AH109A/ MP10 did not show clear cross-resistance to the other antitumor agents currently used for TACE, such as doxorubicin, epirubicin, mitomycin C, 5-fluorouracil, and zinostatin stimalamer, and miriplatin suspension did not cause any hepatic vascular injury preventing repeated TACE (10). These findings suggest hat HCC refractory to miriplatin might be manageable with treatment by other antitumor agents.

There was no apparent difference in intracellular platinum accumulation and platinum-DNA adduct formation between resistant cells and parental cells after treatment with miriplatin suspension, DPC, or cisplatin for three days, consistent with the unchanged expression level of proteins involved in DNA repair. Accordingly, resistance to miriplatin in AH109A/ MP10 cells was not mediated by a mechanism similar to cisplatin resistance, such as reduced drug accumulation, and decreased platinum-DNA adduct formation. Miriplatin, as well as oxaliplatin, contains DACH as a carrier ligand, suggesting that DPC forms similar platinum-DNA adducts to oxaliplatin, but not to cisplatin. Downstream processes that discriminate between oxaliplatin- and cisplatin-DNA adducts are believed to be responsible for the differences in their biological effects because significant conformational differences have been observed between them (19). Mismatch repair proteins (MLH1, MSH6, and MSH2), DNA damage-recognition proteins (HMBG1, TBP, and hUBF), and translesion DNA polymerases (pol $\beta$ and pol $\eta$ ) discriminate between oxaliplatin- and cisplatin-DNA adducts, while nucleotide excision repair and recombination repair do not (20). In this study, AH109A/MP10 cells did not show dysregulated expression of the proteins involved in DNA damage repair, suggesting that increased repair of DNA damage did not contribute to the resistance to miriplatin in AH109A/MP10 cells.

To further evaluate which downstream processes were responsible for acquired resistance to miriplatin, we compared the ability of miriplatin suspension and cisplatin suspension to induce apoptosis. Cisplatin suspension was effective in inducing apoptosis irrespective of cells, while both miriplatin suspension and DPC about 10-times less potently induce apoptosis in AH109A/MP10 than parental cells. This indicated that the phenotype in miriplatin-resistant cells could be caused by defects in triggering apoptosis after platinum-DNA adduct formation. Defects in the apoptotic response in cancer cells are known to be associated with resistance to various chemotherapeutic agents. Bcl-2 family proteins constitute a critical control point in apoptosis regulating mitochondrial permeability transition (15). Increased expression of anti-apoptotic proteins, such as Bcl-2 and Bcl- $\mathrm{x}_{\mathrm{L}}$, impairs apoptosis induced by antitumor platinum complexes, and decreased expression of pro-apoptotic, such as Bax, is involved in resistance (17). Also, it has been reported that pro-apoptotic Bid and PUMA participated in oxaliplatin-induced apoptosis $(21,22)$. The anti-apoptotic Bcl-2 protein level in AH109A/MP10 cells was 3 to 4 times higher than that in parental cells, although no apparent change in the expression level of Bax, Bid, PUMA, or Bcl- $\mathrm{x}_{\mathrm{L}}$ between the two cells was observed. By 
treating AH109A/MP10 cells with miriplatin suspension in the presence of $\mathrm{YC} 137$, we showed that $\mathrm{Bcl}-2$ inhibitor could partially reverse miriplatin resistance. These results suggested that increased expression of Bcl-2 could contribute in part to the resistance to miriplatin in AH109A/MP10 cells. Further studies are needed to identify which factor(s) could be antagonized by Bcl-2 in miriplatin-induced apoptosis. Additionally, to improve knowledge of the mechanism of acquired resistance to miriplatin, we are also establishing human HCC cell line Li-7, resistant to miriplatin or cisplatin, respectively.

In conclusion, the miriplatin-resistant rat hepatoma cell subline AH109A/MP10 established in this study showed clear cross-resistance to platinum complexes containing $\mathrm{DACH}$ as a carrier ligand, but not to cisplatin or the other antitumor agents used for TACE. The acquired resistance to miriplatin in AH109A/MP10 cells was associated in part with increased Bcl-2 expression leading to defects in inducing apoptosis.

\section{Acknowledgements}

The authors are grateful to Junko Kodo for her expert technical assistance.

\section{References}

1. Lo CM, Ngan H, Tso WK, et al: Randomized controlled trial of transarterial lipiodol chemoembolization for unresectable hepatocellular carcinoma. Hepatology 35: 1164-1171, 2002.

2. Llovet JM, Real MI, Montaña X, et al: Arterial embolisation or chemoembolisation versus symptomatic treatment in patients with unresectable hepatocellular carcinoma: a randomised controlled trial. Lancet 359: 1734-1739, 2002.

3. Vogl TJ, Naguib NNN, Nour-Eldin NEA, et al: Review on transarterial chemoembolization in hepatocellular carcinoma: palliative, combined, neoadjuvant, bridging, and symptomatic indications. Eur J Radiol 72: 505-516, 2009.

4. Maeda M, Uchida NA and Sasaki T: Liposoluble platinum (II) complexes with antitumor activity. Jpn J Cancer Res 77: 523-525, 1986.

5. Kishimoto S, Fukui M, Fukushima S and Nakano M: Application of a lipophilic platinum derivative contained in an oily lymphographic agent to intra-hepatic arterial chemotherapy. Reg Cancer Treat 1-2: 25-29, 1992.

6. Hanada M, Baba A, Tsutsumishita Y, Tsutsumishita Y, Noguchi T, Yamaoka $\mathrm{T}$, Chiba $\mathrm{N}$ and Nishikaku $\mathrm{F}$ : Intra-hepatic arterial administration with miriplatin suspended in an oily lymphographic agent inhibits the growth of tumors implanted in rat livers by inducing platinum-DNA adducts to form and massive apoptosis. Cancer Chemother Pharmacol 64: 473-483, 2009.
7. Hanada M, Baba A, Tsutsumishita Y, Noguchi T and Yamaoka T: Intra-hepatic arterial administration with miriplatin suspended in an oily lymphographic agent inhibits the growth of human hepatoma cells orthotopically implanted in nude rats. Cancer Sci 100: 189-194, 2009.

8. Kishimoto S, Noguchi T, Yamaoka T, Fukushima S and Takeuchi Y: Antitumor effects of a novel lipophilic platinum complex (SM-11355) against a slowly-growing rat hepatic tumor after intra-hepatic arterial administration. Biol Pharm Bull 23: 344-348, 2000

9. Okusaka T, Okada S, Nakanishi T, Fujiyama S and Kubo Y: Phase II trial of intra-arterial chemotherapy using a novel lipophilic platinum derivative (SM-11355) in patients with hepatocellular carcinoma. Invest New Drugs 22: 169-176, 2004.

10. Okusaka T, Kasugai H, Ishii H and SM-11355 Japan Study Group: A randomized phase II trial of intra-arterial chemotherapy using a novel lipophilic platinum derivative (SM-11355) in comparison with zinostatin stimalamer in patients with hepatocellular carcinoma. J Clin Oncol 27: abs. 4583, 2009.

11. Kumada T, Nakano S, Takeda I, et al: Patterns of recurrence after initial treatment in patients with small hepatocellular carcinoma. Hepatology 25: 87-92, 1997.

12. Stordal B, Pavlakis N and Davey R: Oxaliplatin for the treatment of cisplatin-resistant cancer: a systematic review. Cancer Treat Rev 33: 347-357, 2007.

13. Wang D and Lippard SJ: Cellular processing of platinum anticancer drugs. Nat Rev Drug Discov 4: 307-320, 2005.

14. Kelland LR: DNA repair enzymes and platinum drug resistance in tumors. Am Assoc Cancer Res Eductional Book, pp209-213, 2008.

15. Danial NN: Bcl-2 family proteins: critical checkpoints of apoptotic cell death. Clin Cancer Res 13: 7254-7263, 2007.

16. Real PJ, Cao Y, Wang R, Nikolovska-Coleska Z, Sanz-Ortiz J, Wang $\mathrm{S}$ and Fernandez-Luna JL: Breast cancer cells can evade apoptosis-mediated selective killing by a novel small molecule inhibitor of Bcl-2. Cancer Res 64: 7947-7953, 2004.

17. Heffeter P, Jungwirth U, Jakupec M, et al: Resistance against novel anticancer metal compounds: differences and similarities. Drug Resist Updates 11: 1-16, 2008.

18. Kishimoto S, Miyazawa K, Terakawa Y, Ashikari H, Ohtani A, Fukushima S and Takeuchi Y: Cytotoxicity of cis-[((1R,2R)1,2-cyclohexanediamine- $\left.N, N^{\prime}\right)$ bis(myristato)]platinum (II) suspended in lipiodol in a newly established cisplatin-resistant rat hepatoma cell line. Jpn J Cancer Res 91: 1326-1332, 2000.

19. Wu Y, Pradhan P, Havener J, Boysen G, Swenberg JA, Campbell SL and Chaney SG: NMR solution structure of an oxaliplatin 1,2-d(GG) intrastrand cross-link in a DNA dodecamer duplex. J Mol Biol 341: 1251-1269, 2004.

20. Chaney SG, Campbell SL, Bassett E and Wu Y: Recognition and processing of cisplatin- and oxaliplatin-DNA adducts. Crit Rev Oncol Hematol 53: 3-11, 2005.

21. Köhler B, Anguissola S, Concannon CG, Rehm M, Kögel D and Prehn JHM: Bid participates in genotoxic drug-induced apoptosis of HeLa cells and in essential for death receptor ligands' apoptotic and synergistic effects. PLoS ONE 3: e2844, 2008.

22. Wang X, Li M, Wang J, et al: The BH3-only protein, PUMA, is involved in oxaliplatin-induced apoptosis in colon cancer cells. Biochem Pharmacol 71: 1540-1550, 2006. 